Supporting Information for

\title{
Ultrafine Particles Emitted Through Routine Operation of a Hairdryer
}

Joseph Nelson Dawson, Kristin E. DiMonte, Matthew J. Griffin, and Miriam Arak Freedman

Department of Chemistry, The Pennsylvania State University, University Park, PA 16802, United States

Summary: This supporting information includes representative time traces for experiments to measure the air exchange rate using $\mathrm{CO}_{2}$ and the particle deposition rate using polystyrene latex spheres. In addition, representative time traces for emission rate measurements of four hairdryers and Scanning Mobility Particle Sizer (SMPS) size distributions are included.
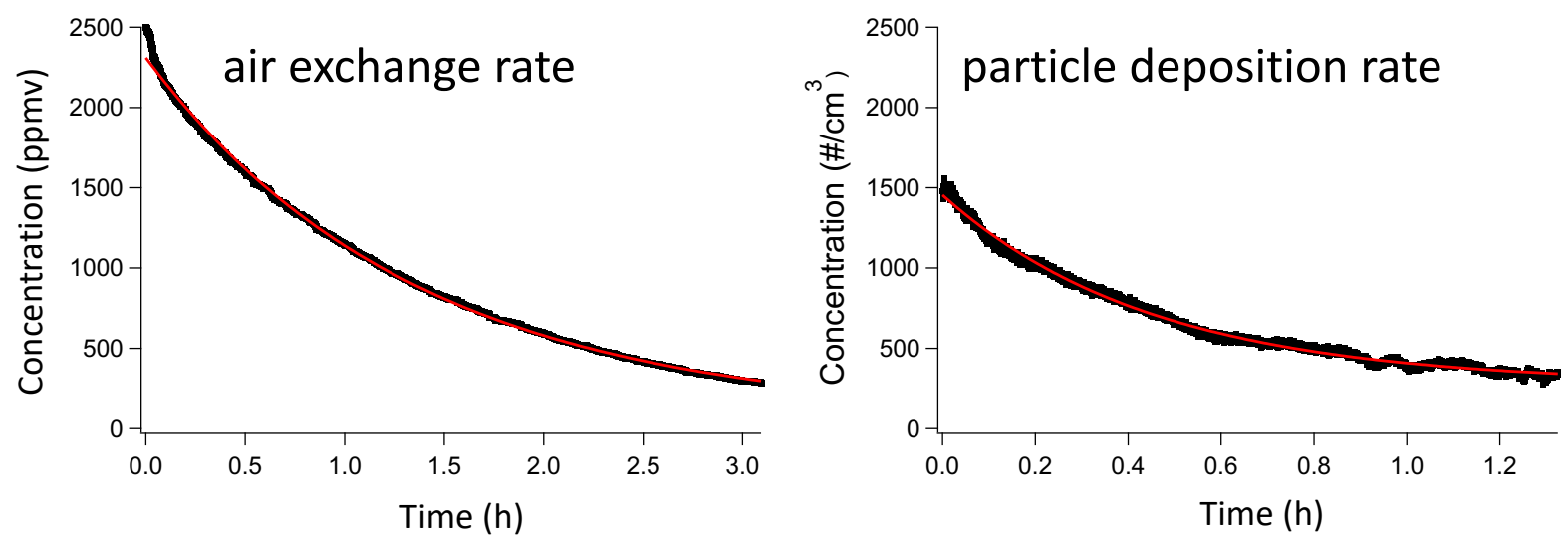

Figure S1. Representative time traces and exponential fits for experiments to measure the air exchange rate using $\mathrm{CO}_{2}$ and the particle deposition rate using polystyrene latex spheres. 

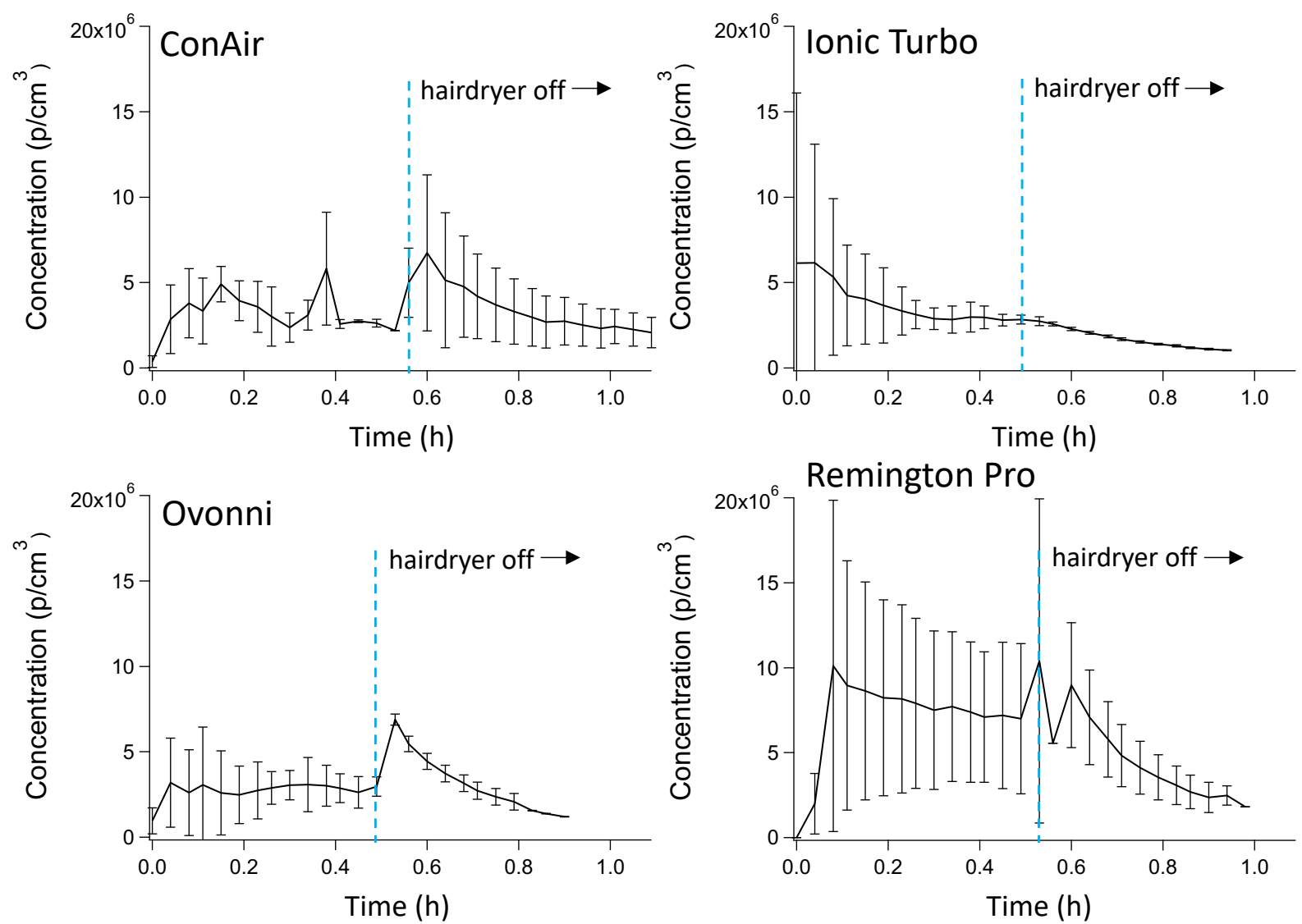

Figure S2. Representative time traces for four hairdryers for emission rate measurements. The hairdryer is shut off after approximately 30 minutes, sometimes resulting in a surge of particles prior to exponential decay. 

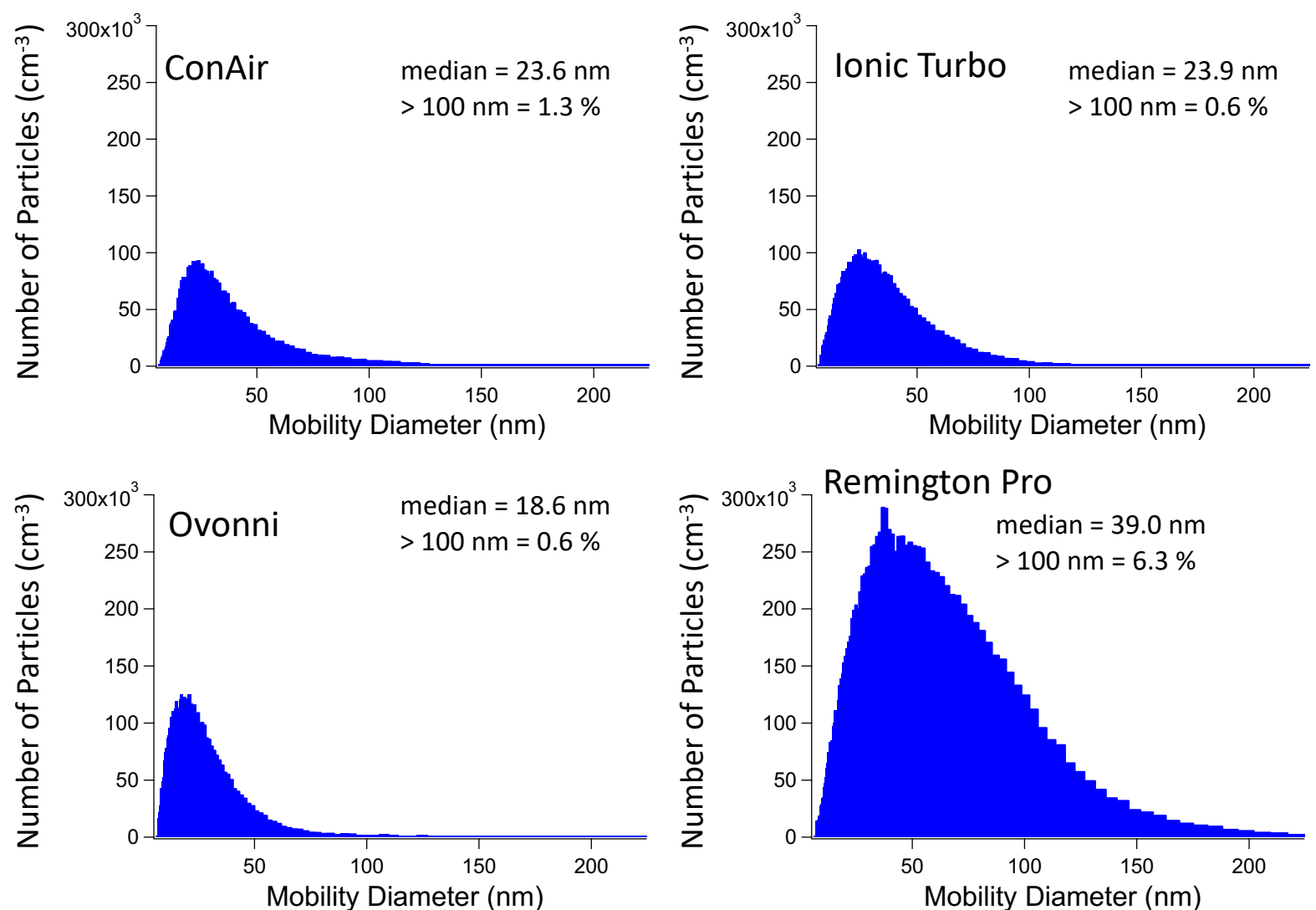

Figure S3. Representative Scanning Mobility Particle Sizer (SMPS) size distributions for four hairdryers showing the median diameter and the percentage of particles $>100 \mathrm{~nm}$ in mobility diameter. 